Original Research Article

\title{
A comparative study on efficacy of nepafenac and flurbiprofen in maintenance of intraoperative mydriasis during cataract surgery: an open label randomized controlled trial
}

\author{
Sanjana Prakash ${ }^{1 *}$, Basavaraj Bhandare ${ }^{1}$, Satyanarayana V. ${ }^{1}$, Kaushal Kumar ${ }^{2}$
}

\begin{abstract}
${ }^{1}$ Department of Pharmacology, ${ }^{2}$ Department of Ophthalmology, Rajarajeswari Medical College and Hospital, Bangalore,

Karnataka, India

Received: 23 January 2018

Accepted: 24 February 2018

*Correspondence to:

Dr. Sanjana Prakash,

Email: dr.sanjanaprakash

@ gmail.com
\end{abstract}

Copyright: (C) the author(s), publisher and licensee Medip Academy. This is an openaccess article distributed under the terms of the Creative Commons Attribution NonCommercial License, which permits unrestricted noncommercial use, distribution, and reproduction in any medium, provided the original work is properly cited.

\begin{abstract}
Background: Surgery on the ocular tissue brings about activation of phospholipase A3 thereby releasing prostaglandins and leukotrienes. Prostaglandins bring about meiosis during surgery, changes in IOP, conjunctival hyperaemia. Newer topical NSAID's Nepafenac and Flurbiprofen are potent inhibitors of the cyclooxygenase enzyme thereby inhibiting the biosynthesis of prostaglandins. Objective of this study was to compare the efficacy of preoperative use of topical Nepafenac $(0.1 \%)$ and Flurbiprofen $(0.03 \%)$ in maintenance of intraoperative mydriasis during cataract surgery.

Methods: A randomised, comparative study was performed on 104 patients, 52 were allocated in each group and were given either of the topical NSAID's Nepafenac or Flurbiprofen prior to cataract surgery. Pupillary diameter was measured at the beginning and at the end of the surgery and the values were compared between the groups. Mean and standard deviation was calculated and between two groups comparison was done using students t-test.

Results: The mean pupillary diameter of the two groups were comparable at the beginning of surgery $(\mathrm{p}=0.34)$. The mean change in the pupillary diameter was $1.86 \pm 0.71 \mathrm{~mm}$ in the Nepafenac group and $1.77 \pm 0.72 \mathrm{~mm}$ in the Flurbiprofen group. There was no statistically significant difference among both the groups in maintenance of intraoperative mydriasis $(\mathrm{p}=0.47)$.

Conclusions: Pre-operative use of Nepafenac and Flurbiprofen were equally effective in preventing meiosis during cataract surgery.
\end{abstract}

Keywords: Cataract surgery, Flurbiprofen, Intraoperative mydriasis, Nepafenac

\section{INTRODUCTION}

Cataract is the chief cause of avoidable blindness in India and throughout the world. There are an estimated 9-12 million blind in India, half of whom can be attributed to cataract. It is estimated that another three million develop visually disabling cataracts each year. ${ }^{1}$ The most effective treatment of cataract is the surgical removal of the clouded natural crystalline lens and its replacement with an artificial intraocular lens (IOL). ${ }^{2}$ Cataract extraction accounts for most of the workload of ophthalmic units worldwide. Extracapsular cataract extraction with posterior chamber intraocular lens implantation (PCIOL) was the most frequent surgical technique until the past decade. ${ }^{1}$

The use of a smaller incision with the advantages of faster rehabilitation, less astigmatism and better postoperative vision without spectacles led to phacoemulsification becoming the preferred technique where resources are available. However, cost, both in terms of equipment and training has limited its use in the developing world. Thus, there is a dichotomy with different standards of care between the developed and the developing world. ${ }^{1}$ 
In developing countries, it is not advisable to do phacoemulsification due to hard nucleus and hyper mature cataract, this requires expensive maintenance equipment's, expensive disposables, expensive foldable lens. Significant efforts are being undertaken to increase the output of cataract surgical services in such countries. Small incision cataract surgery (SICS) has emerged as the most suitable alternative to phacoemulsification to achieve a best unaided visual acuity with rapid postsurgical recovery and minimal surgery related complications. ${ }^{3}$

Ocular tissue is traumatised during surgery leading to the activation of phospholipase A23, and the liberation of two groups of lipid molecules: arachidonic acid (AA) metabolites, and platelet-activating factors (PAFs). Arachidonic acid forms the substrate for further reactions mainly by the cyclo-oxygenase and the lipoxygenase pathways. The main products of the cyclooxygenase pathway are prostaglandins (PGs), and of lipoxygenase pathway are leukotrienes (LTs). Endogenous PGs produce many effects such as: miosis during surgery, postoperative inflammation, increased permeability of the blood-ocular barriers, conjunctival hyperaemia and changes in intraocular pressure. ${ }^{4,5}$

The decrease in pupil diameter can make cataract removal more difficult and increases the risk of surgical trauma, postoperative ocular inflammation, and posterior capsule rupture. It was reported that, when mydriasis is greater than $6 \mathrm{~mm}$, the incidence of posterior capsule rupture was reduced by half. Thus, maintaining adequate pupil dilatation is considered an important part of ensuring smooth cataract removal. ${ }^{2}$

Topical adrenergic agonists, such as phenylephrine in combination with a cholinergic antagonist such as tropicamide or cyclopentolate are used to dilate pupil preoperatively. Nevertheless, in many eyes subsequent onset of meiosis begins soon after the surgeon makes entry to the anterior chamber. ${ }^{6}$

When PG release is inhibited with topical nonsteroidal anti-inflammatory drugs (NSAIDs) applied preoperatively, mydriasis is adequately maintained during surgery, thereby decreasing trans-operative complications such as posterior capsule rupture. ${ }^{7}$

Topical ophthalmic NSAIDs have been shown to be effective in treating a variety of conditions in which prostaglandins are believed to play a causative role, including surgically induced miosis, postoperative inflammation, treatment and prevention of cystoid macular oedema (CME). ${ }^{2}$

The anti-inflammatory action of the NSAIDs is primarily due to the inhibition of the cyclooxygenase enzyme (COX1 and $\mathrm{COX}-2$ ) and due to a decrease in the biosynthesis and the release of the proinflammatory PGs- $\mathrm{PGE}_{2}$, $\mathrm{PGF}_{2 \alpha} \mathrm{PGD}_{2}$ and $\mathrm{PGI}_{2}$. Additional mechanisms like suppressing the leukocyte motility and chemotaxis, inhibiting the inflammatory cytokines and the free radical scavenging activity, may also contribute to their antiinflammatory action. ${ }^{8}$

Nepafenac, a newer topical NSAID, also showed similar favourable effects. It is a prodrug. It is hydrolysed in the intraocular tissues to amfenac, a potent inhibitor of cyclooxygenase-1 (COX-1) and COX-2 enzymes. High ocular bioavailability, permeability and rapid bioactivation by ocular tissues, make it a target specific NSAID for the inhibition of PG formation in the anterior and posterior segments of the eye. Its prodrug structure helps to reduce the risk of toxicity on the corneal surface and enhances its penetration into specific tissues. ${ }^{9}$ Its been approved by FDA for preventing postoperative ocular inflammation and pain. ${ }^{4}$

Flurbiprofen can suppress the TNF- production eventually leading to reduction of leukocyte adhesion and finally developing a good retinal field..$^{10} 0.03 \%$ flurbiprofen and $1 \%$ suprofen are water soluble phenylalkanoic acid and are approved by the US FDA for intraoperative use during cataract surgery to control miosis. ${ }^{4}$

There are not many studies comparing the effects of nepafenac and flurbiprofen. So, this study compares the efficacy of nepafenac and flurbiprofen in cataract surgery and the percentage change in diameter at the end of surgery.

\section{METHODS}

This was a randomised, open label, comparative study conducted on patients posted for cataract surgery under local anaesthesia. The study was conducted from November 2015 to April 2016. Institutional ethics committee approved the study. Written Informed consent was taken prior to the study.

Sample size was calculated with power of $80 \%$, alpha as $0.05 \%$. Author assumed the effect size as $0.8 \mathrm{~mm}$. The standard deviation for flurbiprofen and nepafenac was taken from a previous study as $1 \mathrm{~mm}$, respectively. ${ }^{9}$ Thus, sample size " $n$ " required per group is $n=52$.

\section{Inclusion criteria}

- Patients age 40 years and above with age related cataract

- Patients with unilateral or bilateral cataract undergoing surgery.

\section{Exclusion criteria}

- Patient's allergic to any NSAIDS.

- Patients using NSAIDS, steroids and alpha blockers either topical or systemic, 30 days prior to surgery.

- Patients with hypertension.

- Patients with active ocular inflammation.

- Patients with previous intraocular surgery. 
- Patients with glaucoma and uveitis.

- Patients not willing for the study.

The patients included were randomly allocated by using computer generated random number table into 2 groups with 52 patients in each group

- Group 1: received Nepafenac $0.1 \%$ ocular drops

- Group 2: received Flurbiprofen $0.03 \%$ ocular drops

Patients in each group received the respective topical NSAID drops with a dosage of 1 drop every 15 minutes for 4 times one hour prior to the scheduled operation, the last drop being administered 10 minutes before peribulbar block.

Mydriatic phenylephrine 5\% and tropicamide $0.8 \%$ combination eye drop was given preoperatively to all subjects every 15 minutes for 4 times on the day of surgery. Last drop was administered 15 minutes before the peribulbar block. There was a minimum of 5 minutes difference between the instillation of each eye drops.

All the patients received antibiotic eye drop - moxifloxacin $0.5 \%$ - 4 times per day for 4 days prior to surgery and one drop every hour for 4 hours on the day of surgery. All patients underwent Extra capsular cataract surgery with posterior chamber intraocular lens implantation under peribulbar anaesthesia with lignocaine $(2 \%)$, adrenaline (1: 10,000), sodium hyaluronidase, and bupivacaine $(0.5 \%)$.

The pupillary diameter was measured using Castroviejo Caliper's on the cornea by the ophthalmologist

The readings were taken at 2 times:

1. Before anterior chamber entry

2. At the end of surgery

The primary outcome measure was the change in diameter of the pupil during these two stages of surgery.

Other data collected were age, gender, laterality of the eye operated on, and the corresponding category to which they were assigned. Frequency, percentage, mean and standard deviation were used to describe demographic characteristics and values of pupillary measurements. Unpaired t-test was used to determine differences of pupillary diameter between groups. All analyses were twotailed, with $\mathrm{P}<0.05$ considered as significant. The data was analysed using Microsoft Excel and SPSS version 21. Any adverse drug reactions after the instillation of topical NSAIDS were monitored and documented during the study.

\section{RESULTS}

A total 104 patients were included in the study, 52 patients were randomly allocated into each group (Figure 1).
No intraoperative complications were encountered among these cases. There was no serious treatment related adverse events documented.

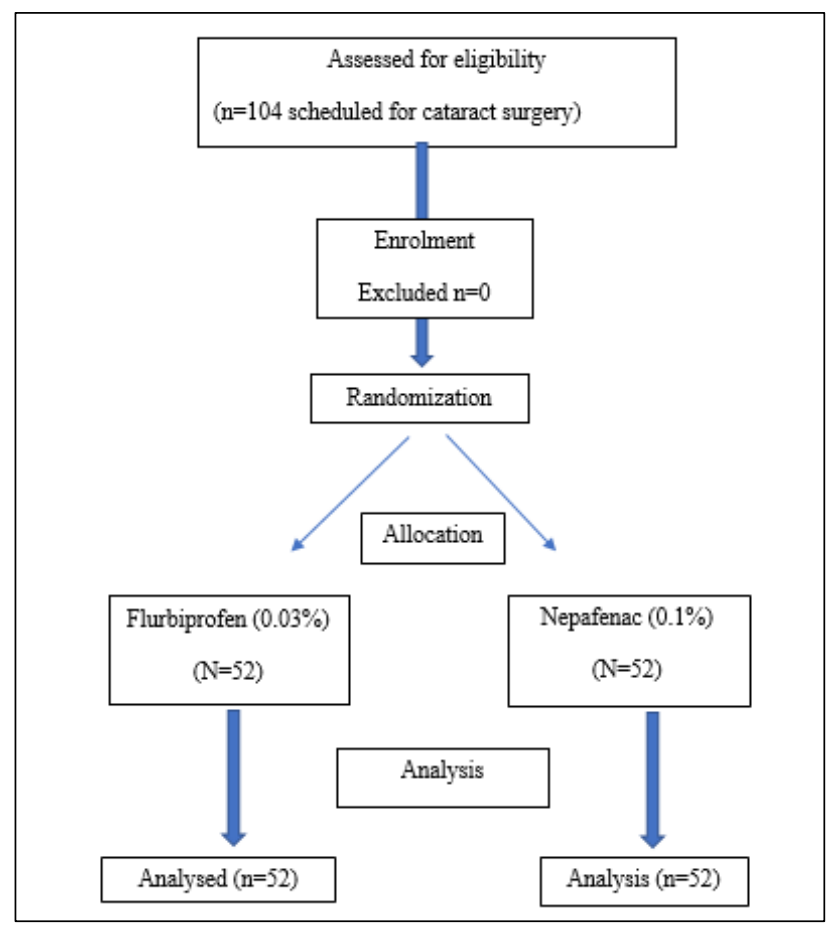

Figure 1: The methodology flowchart.

The demographic characteristics of each group (Table 1). There was no significant difference in age, gender, and laterality of eye operated on among the two groups.

Table 1: Demographic characteristics of patients.

\begin{tabular}{|lll|}
\hline Parameter & $\begin{array}{l}\text { Flurbiprofen } \\
(\mathbf{n = 5 2})\end{array}$ & $\begin{array}{l}\text { Nepafenac } \\
(\mathbf{n = 5 2 )}\end{array}$ \\
\hline Age (years) & & \\
\hline Mean \pm SD & $64.92 \pm 10.91$ & $62.53 \pm 8.5$ \\
\hline Gender & & \\
\hline Male & $30(58 \%)$ & $32(62 \%)$ \\
\hline Female & $22(42 \%)$ & $20(38 \%)$ \\
\hline Laterality of eye & & \\
\hline Right & $21(40 \%)$ & $27(52 \%)$ \\
\hline Left & $31(60 \%)$ & $25(48 \%)$ \\
\hline
\end{tabular}

Table 2 depicts pupillary diameter. Preoperative average pupillary diameter was almost similar in both groups (7.86 $\mathrm{mm}$ and $8.23 \mathrm{~mm}$ in the flurbiprofen and the nepafenac groups, respectively). The difference in pupillary size after surgery was not statistically significant $(\mathrm{p}=0.47)$ $(6.09 \pm 0.74 \mathrm{~mm}$ and $6.36 \pm 1.0 \mathrm{~mm}$ in the flurbiprofen and the nepafenac groups, respectively).

The total reduction in pupil diameter from the beginning to the end of surgery was also statistically not significantly $(\mathrm{p}=0.76)$ different between the flurbiprofen group $(1.77 \pm 0.72 \mathrm{~mm})$ and the nepafenac group $(1.86 \pm 0.71 \mathrm{~mm})$. 
Table 2: Pupillary diameter at different stages of cataract surgery.

\begin{tabular}{|llll|}
\hline Parameter & $\begin{array}{l}\text { Flurbiprofen } \\
(\mathbf{n = 5 2})\end{array}$ & $\begin{array}{l}\text { Nepafenac } \\
(\mathbf{n = 5 2})\end{array}$ & $\begin{array}{l}\mathbf{P} \\
\text { Value }\end{array}$ \\
\hline $\begin{array}{l}\text { Before anterior } \\
\text { chamber entry }\end{array}$ & $7.86 \pm 0.78$ & $8.23 \pm 0.95$ & 0.34 \\
\hline After surgery & $6.09 \pm 0.74$ & $6.36 \pm 1.00$ & 0.47 \\
\hline $\begin{array}{l}\text { Change from } \\
\text { baseline }\end{array}$ & $1.77 \pm 0.72$ & $1.86 \pm 0.71$ & 0.76 \\
\hline $\begin{array}{l}\text { Percentage of } \\
\text { loss }\end{array}$ & $22.54 \pm 4.3$ & $22.65 \pm 3.27$ & 0.48 \\
\hline
\end{tabular}

There was almost similar loss of mydriasis about $22 \%$ in both the groups. This indicates that prophylactic use of flurbiprofen and nepafenac were both equally effective in maintaining mydriasis during cataract extraction.

\section{DISCUSSION}

Miosis due to surgical trauma is one of the most important obstacles that come in the way of a successful cataract surgery. It leads to difficulty in nucleus delivery and makes the eye more vulnerable to serious intraoperative and postoperative complications. ${ }^{11}$

Topical Non-Steroidal Anti-Inflammatory Drugs (NSAIDs) are important group of drugs which help cataract surgeons to reduce intraoperative miosis, and are beneficial in controlling postoperative pain and inflammation. ${ }^{11}$ Several studies compared the effects of topical NSAIDs with placebo in inhibiting miosis during cataract surgery. ${ }^{12-14}$ Many comparative studies showed similar therapeutic efficacy of various ophthalmic NSAIDs with only minor differences in preventing intraoperative miosis. ${ }^{13,15-17}$ The timing regarding installation of NSAIDs drops is still a controversial issue, but the common practice is using topical NSAIDs prior to surgery for desired effects. ${ }^{18}$

In the present study, the preoperative use of flurbiprofen and nepafenac demonstrated maintenance of intraoperative mydriasis during surgery.

The decrease in pupil size was not significantly different between groups flurbiprofen and nepafenac $(\mathrm{p}=0.76)$. A study done by Sarkar et al comparing flurbiprofen and nepafenac concluded that nepafenac is more efficacious in controlling miosis. ${ }^{9}$ They did not include diabetic patients in their study. In this study diabetic patients were included. In Diabetic patients, cytokines and $\mathrm{TNF} \alpha$ - levels are increased in the diabetic retina dur to leukocyte adhesion and breakdown of blood retinal barrier. Flurbiprofen can suppress TNF $\alpha$ production thus inhibiting leukocyte adhesion and breakdown of blood retinal barrier. ${ }^{10}$ This can be one of the reasons why both the drugs were efficacious in the current study.

There was a $22 \%$ decrease in mydriasis at the end of surgery, a study done by Atanis $\mathrm{R}$ et al in which they compared ketorolac and nepafenac in maintenance of mydriasis showed a $30 \%$ and $17 \%$ decrease in mydriasis which is lower than this study even though the eye drops were administered one hour prior to surgery, it was due to a different surgical procedure i.e. phacoemulsification. ${ }^{15}$ Another study done by Bansal $\mathrm{G}$ et al concluded that there was a $6 \%$ and $5 \%$ loss of mydriasis in the nepafenac and bromfenac group which is very low compared to the current study, it can be due to using the drugs one day prior to the surgery whereas in this study we used the drugs on the day of surgery. ${ }^{2}$

A study comparing diclofenac $(0.1 \%)$ and flurbiprofen $(0.03 \%)$ done by Roberts concluded that both the drugs were found equally effective at maintaining mydriasis during cataract surgery. ${ }^{13}$

Gimbel et al compared flurbiprofen and indomethacin and concluded that both are equally effective at maintaining mydriasis during cataract surgery. ${ }^{16}$

In one study done by Zanetti FR found nepafenac $0.1 \%$ was superior to placebo in the inhibition of intraoperative miosis. At the end of surgery, the pupillary diameter for the nepafenac group was $6.9 \pm 0.9 \mathrm{~mm} .^{13}$

Cervantes-Coste et al, showed that nepafenac $0.1 \%$ compared to placebo is effective in maintaining pupillary mydriasis during cataract surgery. The total loss of mydriasis in this study was $0.78 \pm 0.56 .{ }^{17}$

The results of the current study corroborated with other studies that both flurbiprofen and nepafenac are equally efficacious in maintaining mydriasis during cataract surgery. Either of the drugs can be used for maintaining mydriasis. Only few studies are done comparing these drugs. Additional studies are required to confirm our findings probably with a larger sample size and with more parameters to assess the effect and safety of the drugs by including hypertensive patients, taking the vertical pupillary diameter into account, checking for cystoid macular oedema, using other types of surgery, administration of drugs 1-3 days prior to surgery.

\section{CONCLUSION}

Authors conclude that both nepafenac $(0.1 \%)$ and flurbiprofen $(0.03 \%)$ are effective in maintaining adequate mydriasis during cataract surgery.

\section{Funding: No funding sources \\ Conflict of interest: None declared \\ Ethical approval: The study was approved by the Institutional Ethics Committee}

\section{REFERENCES}

1. Gogate PM, Deshpande M, Wormald RP, Deshpande R, Kulkarni SR. Extracapsular cataract surgery compared with manual small incision cataract surgery 
in community eye care setting in western India: a randomized controlled trial. $\mathrm{Br} \mathrm{J}$ Ophthalmol 2003;87:667-72.

2. Bansal G, Gupta S, Kumar S, Kansal S. Comparison of The Effect of Topical Bromfenac With Nepafenac in Maintaining Mydriasis During Cataract Surgery. Delhi J Ophthalmol. 2015;26:97-100.

3. Garg A, Pandey SK, Fry LL, Gutierrez FJ, Tabin G. Clinical Practice in Small Incision Cataract Surgery Phaco Manual, $1^{\text {st }}$ ed. New Delhi: Jaypee Brothers Medical Publishers (P) Ltd. 2004. Clinical Practice in Small Incision Cataract Surgery Phaco Manual.

4. Colin J. The Role of NSAIDs in the Management of postoperative ophthalmic Inflammation. Drugs. 2007;67(9):1291-308.

5. Koay $\mathrm{P}$. The emerging roles of topical non-steroidal anti-inflammatory agents in ophthalmology. $\mathrm{Br} \mathrm{J}$ Ophthalmol. 1996;80(5):480-5.

6. Papa V, Russo S, Russo P, Di Bella A, Santocono M, Milazzo G. Naproxen Study Group. Topical naproxen sodium for inhibition of miosis during cataract surgery. Prospective, randomized clinical trials. Eye (Lond). 2002;16(3):292-6.

7. Podos SM. Prostaglandins, nonsteroidal antiinflammatory agents and eye disease. Trans Am Ophthalmol Soc. 1976;74:637-60.

8. Bannale SG, Pundarikaksha HP, Sowbhagya HN. A Prospective, Open-label Study to Compare the Efficacy and the Safety of Topical Loteprednol Etabonate and Topical Flurbiprofen Sodium in Patients with Post-Operative Inflammation after Cataract Extraction. J Clin Diagn Res. 2012;6(9):1499-503.

9. Sarkar S, Mondal KK, Roy SS, Gayen S, Ghosh A, De RR. Comparison of preoperative nepafenac $(0.1 \%)$ and flurbiprofen $(0.03 \%)$ eye drops in maintaining mydriasis during small incision cataract surgery in patients with senile cataract: A randomized, doubleblind study. Indian J Pharmacol. 2015;47:491-5.

10. Rajanandh MG, Ramasamy C, Raj KM. Individual and additive mydriatic effect of tropicamide with phenylephrine and flurbiprofen in diabetic patients. Eur J Appl Sci. 2012;4:98-100.

11. Sharma AK, Sharma HR, Sharma R, Singh A. A Comparison of Preoperative Topical Dexamethasone
Phosphate Versus Ketorolac Tromethamine in Maintaining Intraoperative Mydriasis During Small Incision Cataract Surgery. J Clin Diagn Res. 2016;10(5):NC09-13.

12. Zanetti FR, Fulco EA, Chaves FR, da Costa Pinto AP, Arieta CE, Lira RP. Effect of preoperative use of topical prednisolone acetate, ketorolac tromethamine, nepafenac and placebo, on the maintenance of intraoperative mydriasis during cataract surgery: A randomized trial. Indian J Ophthalmol. 2012;60:27781.

13. Roberts CW. Comparison of diclofenac sodium and flurbiprofen for inhibition of surgically induced miosis. J Cataract Refract Surg.1996;22:780-87.

14. O'Brien TP. Emerging guidelines for use of NSAID therapy to optimize cataract surgery patient care. Curr Med Res Opin. 2005;21:1131-7.

15. Atanis R, Tuaño PM, Vicencio J, Martinez JM, Verzosa L. Effect of topical ketorolac tromethamine and topical nepafenac on maintaining pupillary dilation during phacoemulsification. Philipp $\mathbf{J}$ Ophthalmol. 2011;36:23-7.

16. Gimbel H, Van Westenbrugge J, Cheetham JK, DeGryse R, Garcia CG. Intraocular Availability and Pupillary Effect of Flurbiprofen and Indomethacin During Cataract Surgery. J Cataract Refract Surg. 1996;22(4):474-9.

17. Cervantes-Coste G, Sanchez-Castro YG, OrozcoCarroll M, Mendoza- Schuster E, Velasco- Barona C. Inhibition of surgically induced miosis and prevention of postoperative macular edema with nepafenac. Clin Ophthalmol. 2009;3:219-26

18. Surhio SA, Memon M, Talpur R, Talpur KI. Efficacy of nepafenac $0.1 \%$ in maintaining mydriasis during phaco emulsification surgery. JLUMHS. 2013;12:748.

Cite this article as: Prakash S, Bhandare B, Satyanarayana V, Kumar K. A comparative study on efficacy of nepafenac and flurbiprofen in maintenance of intraoperative mydriasis during cataract surgery: an open label randomized controlled trial. Int J Basic Clin Pharmacol 2018;7:617-21. 